\title{
La integración de las normas internacionales sobre derechos humanos al derecho penal: una interpretación garantista
}

\author{
The Integration of International Norms on Human Rights to the \\ Criminal Law: An Interpretation from a General Theory of Guarantees \\ A integração das normas internacionais sobre direitos humanos \\ ao direito penal: uma interpretação garantista
}

\author{
JUAN OBERTO SOTOMAYOR ACOSTA ${ }^{* *}$ \\ FERNANDO LEÓN TAMAYO ARBOLEDA ${ }^{* * *}$
}

FeCha de ReCEPCión: 15 de JUlio de 2016. FeCha de ACEPTACión: 9 de AGOSTO de 2017

DOI: http://dx.doi.org/10.12804/revistas.urosario.edu.co/sociojuridicos/a.5014

Para citar este artículo: Sotomayor, J. O., \& Tamayo, F. L. (2018). La integración de las normas internacionales sobre derechos humanos al derecho penal: una interpretación garantista. Estudios Socio-Jurídicos, 20(1), 207-236. doi: http://dx.doi.org/10.12804/revistas.urosario.edu.co/sociojuridicos/a.5014

\section{RESUMEN}

El presente texto se ocupa de analizar la forma en que opera el principio de integración en el derecho penal, ofreciendo una interpretación sobre las relaciones entre los derechos humanos y el derecho penal, y enfatizando las tensiones que se presentan entre las ideologías de expansión del poder punitivo del Estado y la perspectiva garantista; así mismo, analiza el principio de integración de los tratados internacionales en el texto constitucional colombiano a partir del concepto de bloque de constitucionalidad.

Palabras clave: derecho internacional, derecho penal, derecho constitucional, principio de integración, bloque de constitucionalidad.

* Este artículo es producto de la participación de los autores (como coinvestigador y asistente de investigación) en el proyecto de investigación "Las garantías penales como límite y guía en la solución de problemas penales complejos: la necesidad de evitar atajos", dirigido por el profesor Miguel Díaz y García-Conlledo (Universidad de León, España), con financiación del Ministerio de Economía y Competitividad, código DER2013-47511-R, de España; y de la Universidad Eafit, código 621-000008, en Colombia.

** Doctor en Derecho, Universidad de Salamanca (Salamanca, España). Profesor de Derecho Penal, Universidad Eafit (Medellín, Colombia).Correo: jsotoma@eafit.edu.co

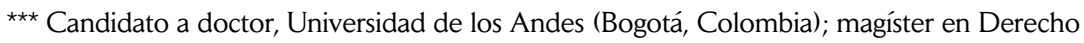
Penal, Universidad Eafit (Medellín, Colombia). Asistente graduado de docencia, Universidad de los Andes (Bogotá, Colombia).Correo: fernandoleontamayo@hotmail.com 


\section{ABSTRACT}

This paper analyses how the principle of integration works in criminal law, offering an interpretation of the relationships between human rights and criminal law, showing the tensions among the State criminal law expansionist ideologies and a right-based perspective. Furthermore, it analyses the principle of integration of international treaties in the Colombian Constitutional text and its relation with the concept of Constitutional Block.

Key words: International law, criminal law, constitutional law, principle of integration, constitutional block.

\section{RESUMO}

O presente texto ocupa-se de analisar a forma em que opera o princípio de integração no direito penal, oferecendo uma interpretação sobre as relações entre os direitos humanos e o direito penal, e enfatizando as tensões que se apresentam entre as ideologias de expansão do poder punitivo do Estado e a perspectiva garantista; assim mesmo, analisa o princípio de integração dos tratados internacionais no texto constitucional colombiano a partir do conceito de bloque de constitucionalidade.

Palavras- chave: Direito internacional, direito penal, direito constitucional, princípio de integração, bloque de constitucionalidade. 


\section{Introducción}

De conformidad con el denominado principio de integración consagrado en el artículo $2^{\circ}$ del Código Penal colombiano (C.P.), "las normas y postulados que sobre derechos humanos se encuentren consignados en la Constitución Política, en los tratados y convenios internacionales ratificados por Colombia, harán parte integral de este código", disposición que suele entenderse como un desarrollo del artículo 93 de la Constitución Política (Const. Pol.) (Pinzón Muñoz, 2012). La similitud de contenidos de ambas normas resalta ya la estrecha relación existente entre el derecho constitucional y el derecho penal, no solo por la jerarquía normativa que la Constitución ostenta en el sistema jurídico, sino por la particular importancia que esta tiene en materia penal, toda vez que desde el punto de vista constitucional el derecho penal puede ser entendido como un mecanismo de protección y de vulneración de derechos fundamentales al mismo tiempo, por lo que la mencionada relación entre estas ramas del derecho debe calificarse, cuando menos, de turbulenta.

En medio de esta relación de permanente tensión, el principio de integración, en tanto garantiza en el ámbito del derecho penal la prevalencia de los derechos humanos ya respaldada por el bloque de constitucionalidad (Uprimny, 2008), se erige en un principio fundamental para la consolidación de una lectura garantista de la legislación penal, en cuanto recurso para validar derechos ya consagrados en otros apartes del texto constitucional, para complementar estos mismos derechos o para ingresar al sistema nuevos derechos de protección del ciudadano. Pese a su innegable valor en este sentido, el principio de integración origina también algunos problemas producto de la compleja interacción de los órdenes constitucional y penal, en tanto este no se ha usado solo como una herramienta para garantizar al ciudadano sus derechos frente al poder punitivo estatal, sino también como justificación de nuevos lugares para el castigo, mediante la imposición de penas de dudosa legitimidad, en cuanto producto de una inaceptable flexibilización del sistema de garantías penales, en particular del principio de legalidad, y/o la deformación de las categorías de imputación penal (Sotomayor, 2013).

Por lo anterior, antes de argumentar la forma en que debe operar el principio de integración en el derecho penal desde una perspectiva 
garantista (Ferrajoli, 1995), se ofrecerá una visión general sobre las relaciones entre los derechos humanos y el derecho penal, enfatizando las tensiones que se presentan entre las ideologías de expansión del poder punitivo del Estado y la perspectiva garantista, sin que en el texto se pretenda realizar un análisis exhaustivo y crítico de los diferentes planteamientos que propugnan por un endurecimiento de la respuesta penal a partir de la protección de los derechos humanos; más bien se partirá de la existencia de dicho debate pero mostrando las contradicciones que tales posturas plantean a un derecho penal liberal. A renglón seguido, se analizará el principio de integración de los tratados internacionales en el texto constitucional a partir del concepto de bloque de constitucionalidad, para concluir precisando los alcances del principio de integración en materia penal desde una perspectiva liberal o garantista.

\section{Los derechos humanos y el derecho penal}

\subsection{La particular sensibilidad hacia el tema de los derechos humanos}

Hablar de derechos humanos en el derecho penal resulta siempre complejo dadas las implicaciones que un sistema de castigo como el actualmente establecido representa en una sociedad. El lugar privilegiado que ocupa la cárcel como mecanismo de castigo y, más aún, la cárcel en la forma en que existe actualmente en Colombia, pone de presente un sistema de precariedades inconmensurables y de una violencia deliberada y de gran magnitud contra seres humanos, que lo convierte en un sistema de castigo cruel, inhumano y degradante, y, por lo tanto, claramente incompatible con el modelo constitucional. ${ }^{1}$

La otra cara del derecho penal presenta a la víctima para recordar que detrás de los juicios penales de imputación de responsabilidad, por lo general, no se encuentra solamente un individuo subyugado por el poder punitivo del Estado, sino también una persona cuyos derechos

\footnotetext{
1 Las condiciones de reclusión carcelaria en Colombia han sido declaradas por la Corte Constitucional, en reiteradas ocasiones, como un estado de cosas inconstitucional; al respecto, sentencias T-153 de 1998, M. P. Eduardo Cifuentes Muñoz; T-388 de 2013, M. P. María Victoria Calle Correa; y T-762 de 2015, M. P. Gloria Stella Ortiz Delgado.
} 
fueron violentados por aquel o por alguien cuya identidad permanece en la oscuridad. En Colombia esta visión se ha visto agravada por la persistencia de un conflicto armado de larga duración (Pérez Toro, 2000), que ha traído como consecuencia la dramatización de la relación entre víctima y victimario, y el traslado al derecho penal de una lógica bélica (Aponte, 2006) que concibe los derechos del imputado en contradicción con los derechos de las víctimas, en un discurso que barbariza al imputado y lo convierte en asocial para negarle sus derechos, al tiempo que la reivindicación de estos derechos es identificada con la promoción de la impunidad y la insensibilidad con el dolor de la víctima.

Ante este escenario, el análisis de las relaciones entre los derechos humanos y el derecho penal debería empezar por la disminución de la carga emocional que media en este tema e intentar una aproximación de la manera más desapasionada posible. Y empezar por asumir, por una parte, que el derecho constitucional impone al derecho penal (y en particular al derecho procesal penal) el deber de garantizar ciertos derechos a las víctimas de actos delictivos; pero, por otra, entender también que ello no significa que el procesado deje de ser el centro del derecho penal, pues es él quien de manera significativa sufre las consecuencias del poder penal estatal y quien corre el riesgo de ser instrumentalizado por dicho poder, razón por la cual su protección se erige en objetivo prioritario del proceso penal. El reconocimiento de este carácter prevalente de las garantías penales y procesales del procesado no tiene por qué significar, sin embargo, una disminución de los derechos de la víctima; se trata más bien de lograr un punto de equilibrio que posibilite la protección de ambos (Ferrajoli, 1995), que desactive ciertos discursos de venganza promovidos por algunos sectores (Beltrán, 1998).

\subsection{Alcances de la protección de los derechos humanos por el derecho penal}

En un sentido amplio es posible afirmar que el derecho penal protege una extensa gama de derechos humanos, algunos de forma directa y otros de manera indirecta. Esta distinción resulta fundamental para entender las relaciones entre derecho penal y Constitución, así como las tensiones existentes entre las posiciones del imputado y la víctima en el 
sistema penal. Por una parte, el derecho penal protege de forma directa los derechos humanos de los perseguidos penalmente, en la medida en que su finalidad prioritaria, y a su vez criterio de legitimidad interna, es precisamente el reconocimiento y respeto de ciertas garantías que funcionan en favor de todo aquel que pueda verse hostigado por el sistema penal (Ferrajoli, 1995).

Por otra parte, el derecho penal protege por regla general de una forma indirecta los derechos de las potenciales víctimas del delito. Se trata de una protección indirecta por cuanto pretende proteger solo hacia el futuro, a través de la amenaza de la pena; por lo tanto, en este caso la protección dispensada no es tanto a una víctima real, sino potencial, por cuanto en el momento de la amenaza penal no existe aún una víctima, por la misma razón que tampoco existe un delincuente: potencialmente todos las personas podrían ser tanto lo uno como lo otro. En esta instancia, en realidad, a través de la amenaza de la pena el derecho penal no pretende proteger a 'las víctimas', sino los bienes jurídicos fundamentales de todos (y no solo de una posible concreta víctima) y solo frente a posibles males futuros; es por eso que la comisión del delito representa ya el fracaso de la finalidad protectora perseguida, por cuanto significa que la pena no fue suficiente para evitar el delito; y quizá no lo fue porque en últimas su función preventiva no depende tanto del contenido de la amenaza penal en sí misma, sino de la eficiencia de los otros controles e instancias de prevención, desde la existencia de una adecuada política social hasta un correcto funcionamiento de la instancia policial. ${ }^{2}$

Podría entenderse, no obstante, que el derecho penal de todas maneras es capaz de brindar alguna protección a la víctima una vez producido el delito, a través del reconocimiento constitucional de sus derechos a la verdad, justicia, reparación y no repetición, ${ }^{3}$ pero también ello plantea algunas incertidumbres. En primer lugar, por cuanto en este caso no se trata de brindar protección a la víctima a partir de la criminalización o la

2 Cabe destacar, además, que la finalidad de prevención perseguida por el derecho penal se encuentra en todo caso condicionada por la satisfacción de la función de garantía de los derechos de los penalmente involucrados, pues las garantías penales y procesales existen precisamente como límites a las necesidades de prevención (Ferrajoli, 1995).

3 Así, CC, sentencias C-228 de 2002, M. P. Manuel José Cepeda Espinosa y Eduardo Montealegre Lynett; y C-209 de 2007, M. P. Manuel José Cepeda Espinosa. 
penalización, sino de garantizarle el acceso al proceso penal para que haga valer allí tales derechos; y, por otra parte, no está del todo claro que la satisfacción de tales derechos corresponda en estricto sentido al derecho penal, pues estos no tienen plena cabida en su modelo de justificación, el cual, centrado en sus funciones de prevención y garantía, no cuenta con un lugar preestablecido para la víctima en su sistema teleológico.

Durante mucho tiempo este modelo tuvo su punto más débil en la ausencia de respuesta al interrogante sobre ¿qué hacer cuando el autor de las violaciones a derechos humanos no se enfrenta al poder punitivo del Estado, sino que es directamente favorecido por este, siendo la víctima quien soporta el enfrentamiento con el leviatán? La pregunta hace referencia a casos, no poco comunes en Latinoamérica, de impunidad estatal concertada, en la que los delitos cometidos son dejados de perseguir por parte del Estado, fundado en un interés ilícito en dicha omisión. El caso modelo de estas situaciones es el de las dictaduras latinoamericanas del siglo $\mathrm{XX}$, en las cuales la negativa a perseguir o juzgar a los culpables puso de presente la enorme desventaja en que las víctimas se encuentran cuando es el propio Estado, como ente encargado de la persecución penal, el que deja de investigar y juzgar el delito para encubrir su propio proceder o para proteger organizaciones paraestatales delictivas que funcionan bajo su aquiescencia. ${ }^{4}$

\subsection{El nuevo punitivismo de la protección de los derechos humanos}

A pesar de las contradicciones que supone derivar de los derechos humanos una concepción retributiva de la justicia, el punitivismo actualmente existente se ha apoyado fuertemente en dicha ideología, con el fin de ampliar el campo de influencia del castigo en la sociedad. ${ }^{5}$

4 En Colombia estos casos no han sido pocos, pues eventos como la retoma del Palacio de Justicia en 1985 o las masacres realizadas por grupos paramilitares con la ayuda activa o pasiva de los órganos estatales permanecen aún sin esclarecer y en la impunidad casi absoluta. Hoy, sin embargo, este tipo de hechos justificaría la intervención de la jurisdicción penal internacional, como se prevé en el Estatuto de Roma (Ambos, 2000).

5 Como explica Pastor (2009, p. 241), el actual constituye un "nuevo derecho penal, contrailustrado, cuyas características deben ser estudiadas bajo la designación de neopunitivismo, en tanto que el rasgo distintivo de este estilo de derecho penal, que engloba todos sus componentes, es su marcada deshumanización y un recrudecimiento sancionador creciente" (cursivas textuales). 
A partir de la legitimidad de que gozan los derechos humanos en la sociedad occidental, ha ganado terreno la idea de garantizar los derechos humanos por la vía penal y reducir o flexibilizar las garantías penales, a fin de facilitar la persecución y castigo de los delitos contra los derechos humanos (Sotomayor, 2013).

Esta concepción se ha visto jalonada en Colombia por interpretaciones extensivas del artículo 93 de la Constitución Política, referido al bloque de constitucionalidad, del cual se ha pretendido derivar un deber de intervención penal frente a aquellas graves violaciones de los derechos humanos representadas en los crímenes de guerra y de lesa humanidad, que ha permitido, por ejemplo, condenas por delitos inexistentes al momento de la comisión del hecho, argumentando que por mandato del derecho internacional y, más específicamente, de las normas constitucionales que integran dicha normatividad al ordenamiento jurídico colombiano, tales conductas estaban criminalizadas a pesar de que el legislador colombiano no hubiese creado de manera expresa la figura delictiva correspondiente.

Fue este, por ejemplo, el argumento utilizado por la Corte Suprema de Justicia (CSJ) en la sentencia del 15 de mayo de 2013 sobre la 'masacre de Segovia', en la cual se condenó y se impuso la pena de un delito prescrito (homicidio), para lo cual se aplicó la consideración de delito imprescriptible del genocidio, delito que, sin embargo, no se encontraba vigente al momento de la comisión de los hechos (C.P. de 1980) y cuyos elementos en el caso eran bastante discutibles. ${ }^{6}$ Esta posición de la CSI necesita olvidar o, más comúnmente, reformular la idea del principio constitucional de legalidad, remplazándola por una legalidad que incluye dentro de las fuentes del derecho penal los delitos suscritos en tratados internacionales y el ius cogens, dejando de lado que las prohibiciones penales deben ser siempre derivadas de la ley como única fuente.

Así mismo, si se admite la propuesta de la CSJ de que las normas internacionales que imponen la obligación de incorporar ciertos delitos al ordenamiento jurídico integran el bloque de constitucionalidad, habría

Sobre esta característica de los sistemas penales en la actualidad puede verse con carácter general a Silva Sánchez (2001).

6 En claro desconocimiento de la exigencia constitucional de ley previa al hecho. Sobre la flexibilización del principio de legalidad en la persecución de los delitos de lesa humanidad, ver las consideraciones críticas de Álvarez (2012). 
que aceptar en estos casos la existencia de mandatos de criminalización, ${ }^{7}$ lo que obligaría al legislador a establecer legalmente no solo el comportamiento penalmente prohibido ${ }^{8}$ sino la sanción correspondiente, pues, de no existir dicha previsión legal, el juez, aunque reconozca que la Constitución ordena criminalizar dichas conductas, tendría las manos atadas en tanto no existan de forma previa el delito y la pena, como lo exige el principio de legalidad. En otras palabras, si existiesen mandatos de criminalización, tal perspectiva encuentra en el principio de legalidad un obstáculo insalvable, pues de considerarse necesaria dicha protección el asunto debería ser visto más bien como un problema constitucional a solucionar por vía de la incorporación de los delitos al Código Penal mediante el procedimiento legislativo.

En estos casos, si el delito estuviera prescrito, no es posible ninguna acción legal interna de carácter penal y solo podrían operar los mecanismos previstos por el derecho internacional: la posible intervención de la Corte Penal Internacional (CPI), si se cumplen los demás presupuestos, y la posible responsabilidad del Estado por omisión al incumplir su compromiso de llevar tales normas internacionales al ordenamiento jurídico interno y por no juzgar el hecho de manera oportuna.

No obstante, hay que subrayar que el escenario anterior solo se daría si se admite que las normas internacionales incriminatorias también integran el llamado bloque de constitucionalidad, lo cual no pareciera derivarse directamente del artículo 93 de la Constitución Política, cuyo objetivo parece orientarse más bien a la ampliación de las garantías del individuo frente al poder penal del Estado y no al revés, esto es, a la extensión del poder penal estatal más allá de las garantías constitucionalmente reconocidas.

Sobre la existencia de un derecho al castigo por parte de las víctimas de graves violaciones de los derechos humanos, o incluso de la sociedad

7 Aun cuando en todo caso dicho deber tendría que ser ponderado con otros principios constitucionales con los que tal mandato podría entrar en contradicción, lo que haría necesario siempre un juicio de proporcionalidad al respecto (Lopera Mesa, 2006).

8 Por cuanto la tipificación no tiene necesariamente que coincidir con la convencional, tal como ha sucedido en Colombia con la tipificación del delito de genocidio (C.P., art. 101), que incluye como conducta típica la conducta orientada a la destrucción total o parcial de grupos políticos, circunstancia que no aparece recogida en la Convención contra el Genocidio (Ley 28 de 1959). 
misma, se ha debatido en la jurisprudencia nacional e internacional, lo que ha permitido un incremento del poder de los jueces para expedir condenas, la flexibilización de los principios penales clásicos y la creación de una especie de derecho al castigo (al respecto: Pastor, 2009). Sin embargo, esta posición no suele ser sostenida en los mismos términos filosóficos, ${ }^{9}$ pues la mayoría de textos que se ocupan del tema remiten a la regulación o jurisprudencia internacional sobre persecución y juzgamiento de graves violaciones contra los derechos humanos, sin llegar a una postura filosóficamente fundamentada. ${ }^{10}$

\section{Constitución, bloque de constitucionalidad y derecho penal}

El artículo 93 de la Constitución Política establece que los tratados y convenios internacionales que consagren derechos humanos y prohíban su limitación en los estados de excepción serán prevalentes en el orden jurídico nacional; así mismo, se indica que los derechos y deberes consagrados en la Constitución se interpretarán de conformidad con los tratados internacionales sobre derechos humanos ratificados por Colombia. Esta fórmula realiza la integración de normas internacionales con normas constitucionales, otorgándoles a las primeras el carácter prevalente en el orden nacional; por ello, la determinación de los alcances del principio de integración penal presupone a su vez el del bloque de constitucionalidad, en tanto el mencionado principio, como ya se indicó, suele entenderse como desarrollo de la disposición constitucional.

\subsection{El bloque de constitucionalidad}

El artículo $4^{\circ}$ de la Carta Política consagra que las disposiciones de la Constitución Política serán prevalentes en todo el orden jurídico, en tanto

9 Algunas propuestas de flexibilización de los principios penales o del derecho al castigo han sido elaboradas por activistas de los derechos humanos, como es el caso de Beltrán (1998), exdirector de una de las secciones de Amnistía Internacional.

10 Además de los citados, se puede remitir a las obras de Roht-Arriaza (1990), Méndez (1997), Arango Olaya (2004), Doménech Pascual (2006) y Fajardo Arturo (2009), entre otros. 
el artículo 93 afirma que los tratados internacionales ratificados por el legislador, que consagran derechos humanos y prohíben su limitación en estados de excepción, prevalecen en el orden jurídico interno. Luego, al existir dos disposiciones constitucionales que declaran la prevalencia de diferentes órdenes normativos, no puede evitarse la pregunta sobre cuál de los dos ordenamientos resulta prevalente, asunto que ha sido resuelto por la Corte Constitucional (CC) en el sentido de que las normas que incorporan derechos humanos y prohíben su limitación en Estados de excepción poseen el mismo rango de las normas constitucionales, para lo que se vale del concepto de bloque de constitucionalidad.

La idea que subyace al bloque de constitucionalidad ha sido usada por la CC a partir de la Sentencia C-574 de 1992, en la que, a pesar de no usarse esta expresión, se admitió que existían normas que, siendo externas al texto constitucional, lo integraban; el término 'bloque de constitucionalidad' comenzó a usarse desde la Sentencia C-225 de 1995, en la cual se afirmó que este

[...] está compuesto por aquellas normas y principios que, sin aparecer formalmente en el articulado del texto constitucional, son utilizados como parámetros del control de constitucionalidad de las leyes, por cuanto han sido normativamente integrados a la Constitución, por diversas vías y por mandato de la propia Constitución. Son pues verdaderos principios y reglas de valor constitucional, esto es, son normas situadas en el nivel constitucional, a pesar de que puedan a veces contener mecanismos de reforma diversos al de las normas del articulado constitucional stricto sensu. ${ }^{11}$

A lo anterior se sumó la distinción entre bloque de constitucionalidad en sentido lato y estricto:

[...] resulta posible distinguir dos sentidos del concepto de bloque de constitucionalidad. En un primer sentido de la noción, que podría denominarse bloque de constitucionalidad strictu sensu, se ha considerado que se encuentra conformado por aquellos principios y normas de valor constitucional, los que se reducen al texto de la Constitución propiamente

11 CC, Sentencia C-255 de 1995, M. P. Alejandro Martínez Caballero. 
dicha y a los tratados internacionales que consagren derechos humanos cuya limitación se encuentre prohibida durante los estados de excepción (C.P., art. 93) [...] Más recientemente, la Corte ha adoptado una noción lato sensu del bloque de constitucionalidad, según la cual aquel estaría compuesto por todas aquellas normas, de diversa jerarquía, que sirven como parámetro para llevar a cabo el control de constitucionalidad de la legislación. Conforme a esta acepción, el bloque de constitucionalidad estaría conformado no sólo por el articulado de la Constitución sino, entre otros, por los tratados internacionales de que trata el artículo 93 de la Carta, por las leyes orgánicas y, en algunas ocasiones, por las leyes estatutarias. ${ }^{12}$

No obstante, el contenido del bloque de constitucionalidad no está del todo claro, en tanto la misma corporación ha interpretado el mencionado artículo con alcances diferentes, pues en algunas ocasiones ha dicho que la integración al bloque de constitucionalidad solo procede frente al reconocimiento de derechos humanos cuya limitación se encuentra prohibida en los estados de excepción, ${ }^{13}$ pero también en otras amplía el concepto, en virtud del párrafo 2 del artículo 93, a prácticamente todos los derechos recogidos en convenios y tratados de derechos humanos, con independencia de que se trate de derechos limitables o no en los estados de excepción. ${ }^{14}$

Respecto del artículo 93 de la Constitución Política, parece plausible la interpretación propuesta por Uprimny (2005), quien entiende que el párrafo primero de dicho artículo se refiere solo a los derechos intangibles, esto es, no limitables en los estados de excepción, respecto de los cuales la Constitución establece un mandato de incorporación, en cuanto señala su prevalencia en el orden interno. Así entendido, este deber de incorporación permitiría, por ejemplo, entre otras normas, la inclusión en

12 CC, Sentencia C-191 de 1998, M. P. Eduardo Cifuentes Muñoz. Esta definición primigenia de bloque de constitucionalidad fue posteriormente confirmada, entre otras, en las sentencias C-578 de 1995, M. P. Eduardo Cifuentes Muñoz; C-358 de 1997, M. P. Eduardo Cifuentes Muñoz; C-191 de 1998, M. P. Eduardo Cifuentes Muñoz; C-203 de 2005, M. P. Manuel José Cepeda Espinosa; y C-454 de 2006, M. P. Jaime Córdoba Triviño.

13 CC, Sentencia C-578 de 1995, M. P. Manuel José Cepeda Espinosa.

14 Por ejemplo, CC, sentencias T-483 de 1999, M. P. Álvaro Tafur Galvis; y T-1319 de 2001, M. P. Rodrigo Uprimny. 
el texto constitucional del artículo $2^{\circ}$ de la Convención contra la Tortura y otros Tratos Crueles, Inhumanos y Degradantes (Ley 70 de 1986), según el cual "no podrá invocarse una orden de un funcionario superior o de una autoridad pública como justificación de la tortura", pese a no existir dicha prohibición de manera expresa en la Carta Política, toda vez que el derecho a no ser torturado es intangible incluso en estados de excepción (Bernal Cuéllar, 2003; y Uprimny, 2005).

El segundo párrafo, por su parte, se entiende referido a los derechos y deberes ya reconocidos por la Constitución, frente a los cuales impone el deber de una interpretación conforme a los tratados de derechos humanos ratificados por Colombia (Uprimny, 2005). En este último caso debe destacarse, por una parte, la relevancia de la cláusula hermenéutica de favorabilidad, que obliga a aplicar la regulación más favorable al derecho involucrado, cuando existan diferencias en la regulación de este entre el derecho interno y el tratado o convenio internacional (Pinto, 1997) $i^{15}$ y, por otra, la interpretación conforme a los tratados implica también, de manera indirecta, la incorporación de la jurisprudencia de las instancias internacionales encargadas de fijar el alcance de los respectivos tratados (Uprimny, 2005).

Quizás el mejor ejemplo de ello lo constituya el tema de las víctimas del delito, cuyos derechos en el proceso penal fueron ampliados de manera considerable en virtud de la aplicación en el orden interno de las normas internacionales sobre derechos humanos y, muy especialmente, de las doctrinas elaboradas por los organismos internacionales, en particular por la Corte Interamericana de Derechos Humanos (CIDH).

\subsection{El bloque de constitucionalidad como interpretación} conforme a los tratados internacionales de derechos humanos (Const. Pol., art. 93, párr. 2): el caso de los derechos de las víctimas en el proceso penal

Un ejemplo de interpretación conforme a los tratados de derechos humanos y a las interpretaciones que de ellos han realizado los órganos

15 Este principio ha sido también reconocido por la CC, sentencias C-406 de 1996, M. P. Hernando Vergara Herrera; y C-251 de 1997, M. P. Alejandro Martínez Caballero. 
competentes podría ser el de los derechos de las víctimas (Uprimny, 2008), toda vez que el artículo 229 de la Constitución Política, si bien reconoce el derecho de todos los ciudadanos a acceder a la administración de justicia, no regula con claridad cuáles son los derechos particulares que tiene una persona que ha sido víctima de un delito. En este sentido, la CC, a partir de la Sentencia C-228 de 2002, ha reconocido en el proceso penal a las víctimas no solo el derecho a la reparación del que tradicionalmente han gozado, sino también el derecho a la verdad y a la justicia, ${ }^{16}$ hasta el punto de que tales derechos no tienen discusión hoy en día en el proceso penal en Colombia.

Quizá lo discutible de la interpretación de la Cc está en que ha dado lugar a una identificación mecánica de los alcances de los derechos de las víctimas en juicios de responsabilidad estatal por la violación de derechos humanos -que es en los que han sido interpretados por la CIDH, o en el ámbito de una justicia de transición-, y su significación en el ámbito del proceso penal. Esto ha sido sostenido desde dos perspectivas distintas: por un lado, en la teoría de la CC que afirma que la jurisprudencia internacional, al igual que otras decisiones no vinculantes de los organismos internacionales, son criterios hermenéuticos en materia penal para el juez. Según la CC,

[...] en esta materia es particularmente relevante la doctrina elaborada por la Corte Interamericana de Derechos Humanos, que es el órgano judicial autorizado para interpretar autorizadamente [sic] la Convención Interamericana. En efecto, como lo ha señalado en varias oportunidades esta Corte Constitucional, en la medida en que la Carta señala en el artículo 93 que los derechos y deberes constitucionales deben interpretarse "de conformidad con los tratados internacionales sobre derechos humanos ratificados por Colombia", es indudable que la jurisprudencia de las instancias internacionales, encargadas de interpretar esos tratados,

16 Uprimny (2008) destaca en este cambio jurisprudencial la influencia de la doctrina de la $\mathrm{CIDH}$, en particular la sentencia del 14 de marzo de 2001, caso Barrios Altos (Chumbipuma Aguirre y otros vs. Perú). Las sentencias más relevantes de la CC son las C-228 de 2002, M. P. Manuel José Cepeda Espinosa y Eduardo Montealegre Lynett; y C-578 de 1995, M. P. Eduardo Cifuentes Muñoz. 
constituye un criterio hermenéutico relevante para establecer el sentido de las normas constitucionales sobre derechos fundamentales. ${ }^{17}$

Por otro lado, el Consejo de Estado ha sostenido que los criterios de prescripción operan indistintamente para todo el ordenamiento cuando se trata de casos relacionados con violaciones de los derechos humanos. ${ }^{18}$

Al respecto, no parece tener el mismo sentido y justificación plantearse el derecho a la verdad y a la justicia en el marco de graves violaciones a derechos humanos como los representados por los delitos de lesa humanidad y los crímenes de guerra (en los que, por lo demás, los responsables suelen ser agentes estatales $\mathrm{o}$, en todo caso, de organizaciones armadas poderosas), que en relación con otro tipo de delitos producto de la criminalidad común, o en el derecho penal, orientado teleológicamente por las teorías de justificación de la pena, y el derecho administrativo. La gran paradoja de la jurisprudencia constitucional sobre la extensión de los derechos de las víctimas en el proceso penal ha sido que, buscando amparar a víctimas indefensas frente a graves actos de organizaciones poderosas (incluyendo la estatal), ha facilitado que en los casos del día a día de la justicia penal también poderosas empresas trasnacionales y el propio Estado acudan al proceso reclamando verdad, justicia y reparación frente a individuos prácticamente indefensos acusados de violación a los derechos de autor, hurtos, peculados, etc.

\subsubsection{El derecho a la verdad y sus límites en el proceso penal}

La exigencia de una verdad histórica respecto de lo ocurrido en el pasado parece tener una connotación muy diferente cuando se realiza en el enjuiciamiento a un Estado en particular, o en situaciones de transición, eventos en los que está más que justificada la pretensión de las víctimas de graves delitos de conocer los hechos y circunstancias en que se dieron dichas violaciones, así como el derecho de toda la sociedad a saber los motivos por los cuales se produjeron, con miras a preservar la memoria

17 CC, Sentencia C-067 de 2003, M. P. Marco Gerardo Monroy Cabra.

18 Consejo de Estado, sentencia Expediente 25000-23-26-000-2012- 00537-01 (45092), M. P. Jaime Orlando Santofimio Gamboa. 
colectiva y a evitar de esa manera que hechos de esta índole vuelvan a presentarse. ${ }^{19} \mathrm{~A}$ tal efecto no parece estrictamente necesario que deba ser una verdad judicialmente construida, pues en no pocas ocasiones una verdad por fuera de la rigidez de un proceso judicial facilita el recurso a múltiples medios de acceso a ella.

Muy diferente resulta plantearse la satisfacción de un derecho a la verdad en el marco de un proceso penal, que en principio se orienta de manera prioritaria a la determinación de la posible responsabilidad penal del procesado. Por esta razón, en sentido estricto, el proceso penal no pretende el esclarecimiento de la verdad histórica, sino solo el establecimiento de la verdad en función de la hipótesis de hecho de una determinada figura delictiva, con el agravante adicional, dado que el proceso también debe proteger al procesado frente a posibles abusos, de limitar la averiguación de la verdad al respeto a ciertas reglas sobre admisibilidad de la prueba, contradicción, etc. (Pastor, 2009).

Mirado desde el punto de vista del proceso penal, el derecho a la verdad enfrenta adicionalmente evidentes problemas de efectividad, dada la limitada capacidad estatal para investigar todos los delitos y, en particular, para investigar sucesos complejos cuyo esclarecimiento dista de ser sencillo. ${ }^{20}$ Además, en algunas ocasiones el derecho a la verdad resulta imposible de satisfacer incluso cuando se ha declarado la culpabilidad del procesado, como ocurre en algunos casos de desaparición forzada, en los que se puede lograr la prueba de todos los elementos que configuran dicho delito y ni aun así se llega a esclarecer el paradero del desaparecido o si este sigue con vida o no.

Es por ello que en delitos que suponen graves atentados contra los derechos humanos la satisfacción del derecho a la verdad requiere, cuando menos, complementarse (Uprimny y Saffon Sanín, 2006) con espacios extrapenales y/o extrajudiciales de esclarecimiento de la verdad, no solo por las restricciones inherentes a la verdad judicial, sino porque una

19 Sobre el particular, Uprimny y Saffon Sanín (2006a) remiten a los denominados 'Principios Joinet'. Por su parte, la CC ha entendido el derecho a la verdad como "la posibilidad de conocer lo que sucedió y en [sic] buscar una coincidencia entre la verdad procesal y la verdad real" (Sentencia C-228 de 2002, M. P. Manuel José Cepeda Espinosa y Eduardo Montealegre Lynett, p. 38).

20 Esta situación ya fue puesta de presente en el clásico análisis abolicionista de Hulsman y Bernat de Celis (1984). Esta dificultad también es destacada por Uprimny y Saffon Sanín (2006a). 
narración de los hechos sin la amenaza del castigo inminente podría acercar más a autores y a sus víctimas a la verdad real. Su reconocimiento en el proceso penal, por el contrario, se reduce a la garantía de acceso a la verdad que pueda ofrecer el proceso, lo cual se concreta en el derecho a ser reconocido como posible víctima, incluso desde la indagación, y a participar en todas las actuaciones, tal como se reconoce en los artículos 11 y 132 a 137 del Código de Procedimiento Penal, Ley 906 de 2004 (CPP). Lo que resulta inaceptable es entender el proceso penal como escenario idóneo para satisfacer el derecho de las víctimas al esclarecimiento de la verdad real o histórica, pues ello significaría el fin del derecho y el proceso penal como garantía frente a la desmesura de las pretensiones punitivas (públicas y privadas).

\subsubsection{El derecho a la justicia y sus límites en el proceso penal}

Tampoco es claro el contenido del derecho de la víctima a la justicia y, por ende, tampoco es fácil determinar cómo puede ser satisfecho en el ámbito de un proceso penal (Silva Sánchez, 2008). La CIDH, por ejemplo, en el 'caso Almonacid', ha entendido que el derecho de las víctimas a la justicia se concreta en el derecho "a que se investigue, se identifique y se juzgue a los individuos responsables" ${ }^{\prime 21}$ sin embargo, en no pocas ocasiones dicho derecho suele identificarse con la ausencia de impunidad, lo cual parece incorporar una especie de derecho al castigo del autor. Así, en el 'caso Moiwana', la CIDH entiende la impunidad "como la falta en su conjunto de investigación, persecución, captura, enjuiciamiento y condena de los responsables de las violaciones de los derechos protegidos por la Convención Americana", 22 definición que podría conducir a una identificación del derecho a la justicia con la efectiva condena del autor (Silva Sánchez, 2008). Ello, en realidad no es posible, salvo que en el fondo no se trate de hacer justicia, sino simplemente de encubrir la venganza institucionalizada (Silva Sánchez, 2008). Privar a las víctimas del lúgubre placer de ver a su victimario entre rejas no debe ser

${ }^{21} \mathrm{CIDH}$, sentencia del 26 de septiembre de 2006 (caso Almonacid Arellano y otros vs. Chile), párr. 83b.

$22 \mathrm{CIDH}$, sentencia del 15 de junio de 2005 (caso de la Comunidad Moiwana vs. Suriname), párr. 203. 
entendido como una injusticia, pues, aunque se admita la existencia de víctimas vengativas cuya idea de justicia está profundamente arraigada en el padecimiento físico del victimario, también existen suficientes razones para creer que no todas las víctimas tienen una tal concepción de la justicia (Hulsman y Bernat de Celis, 1984), ni entienden el castigo penal como la única forma de sanción posible dentro del derecho. Por lo mismo no parece sensato derivar de los derechos humanos una justicia meramente retributiva, pues, por el contrario, estos sugieren más bien un amplio margen más allá de la pena y también otras formas de justicia, transicionales o restaurativas ${ }^{23} \mathrm{e}$, incluso, distributivas.

En el afán por castigar se ha perdido de vista que la idea de justicia apoyada en la garantía de los derechos humanos resulta pervertida por las múltiples violaciones cometidas en su difusión y promoción. Así, la idea internacional de justicia ha venido fundándose cada vez más en el castigo como herramienta única, y la retribución como justificación predilecta. ${ }^{24}$ Esto no ha sido óbice para el apoyo internacional a procesos de justicia transicional, pero se ha manifestado en la creciente jurisprudencia internacional -y su impacto en la jurisprudencia nacional- basada en la idea del castigo a toda costa como único mecanismo para garantizar los derechos de las víctimas, pues, pareciera que solo el castigo penal puede ofrecer a las víctimas la verdad, la justicia, la reparación y la no repetición (Castex, 2008).

Ante el panorama descrito, no resulta extraño que los derechos humanos se hayan convertido en el mejor argumento para la existencia del derecho penal y de la cárcel como mecanismo predilecto de castigo.

La preocupación creciente en el ámbito internacional por el problema de la impunidad, elemento por considerar siempre que se alude a la justicia, ${ }^{25}$ entendida como "la falta en su conjunto de investigación, persecución, captura, enjuiciamiento y condena de los responsables de las

23 Sobre la distinción entre justicia transicional y justicia restaurativa, Uprimny y Saffon Sanín (2006b).

24 Cfr. Pastor (2006), Nanzer (2009) y Castex (2008).

25 Precisamente, la CC, Sentencia C-228 de 2002, M. P. Manuel José Cepeda Espinosa y Eduardo Montealegre Lynett, confirma que el derecho de las víctimas a la justicia se traduce en el derecho a que no haya impunidad. 
violaciones de los derechos protegidos por la Convención Americana", ${ }^{26}$ revela el interés internacional por la sanción penal, en especial de los delitos contra los derechos humanos, convirtiéndolos en razón de necesidad y justificación del derecho penal.

Identificar el derecho de las víctimas a la justicia con el castigo efectivo contradice los fundamentos constitucionales del proceso penal mismo, pues en realidad autor culpable solo existe a partir de la sentencia condenatoria y por las mismas razones solo en ese momento puede en estricto sentido hablarse en derecho de la existencia de una víctima; como explica Silva Sánchez (2008, pp. 170-171), "no se es víctima (en sentido jurídico-penal) por el hecho de haber sufrido un daño, sino sólo por haber sufrido una lesión antijurídica, lo que únicamente puede determinarse en el proceso"; luego, ni siquiera un supuesto derecho al castigo del autor en cabeza de la posible víctima podría contraponerse a los derechos y garantías del procesado, quien, mientras no exista una sentencia condenatoria en firme, es solo un posible responsable y, por lo tanto, también, un inocente.

A pesar de los crecientes esfuerzos nacionales e internacionales por construir el concepto de justicia de la mano de una visión cercana a la de un derecho de las víctimas a que los perpetradores sean castigados, en un juego de suma cero en el cual esto implica la flexibilización de los principios constitucionales y penales, lo cierto es que la literatura jurídicopenal aborda dichas posturas de una forma particularmente crítica ${ }^{27} \mathrm{o}$, cuando menos, correctiva (Doménech Pascual, 2007), en el entendido de que es necesario buscar formas de coexistencia entre la necesidad (si es que existe) de castigar y los principios penales de protección frente al poder punitivo. Por ello, no sorprende que los esfuerzos por defender aquel proceder vengan dados por entidades o personas involucradas dentro del proceso mismo.

Por lo tanto, también el derecho a la justicia, al final, se concreta en el derecho al proceso, esto es, a que se investigue y se juzgue a los posibles responsables, lo que para la presunta víctima representa a su vez el

26 CIDH, sentencia del 15 de junio de 2005 (caso de la Comunidad Moiwana vs. Suriname).

27 Cfr. Pastor (2004, 2006, 2009), Nanzer (2009), Castex (2008), Silva Sánchez (2008), entre otros. 
derecho a que se le reconozca también personería en el proceso penal y se le permita actuar en sus diferentes fases en defensa de sus intereses, ${ }^{28}$ en el marco de un debido proceso.

\subsubsection{La contraposición de los derechos de las víctimas $y$ los del procesado}

En la dinámica del punitivismo existente, el recurso a los derechos de las víctimas ha jugado un papel muy significativo, no como autores directos de demandas de punición en virtud de transformaciones en la cultura del control (Garland, 2005) o del denominado fenómeno del populismo punitivo (Pratt, 2007), sino como recurso retórico de un discurso político criminal orientado simplemente al eficientismo, que instrumentaliza cualquier discurso que pueda ser útil para justificar la reducción de garantías y, por ende, facilitar la condena (Sotomayor, 2007). De esta manera se ha construido un discurso político criminal de los derechos de las víctimas en contraposición directa a los derechos y garantías del procesado, de la mano de unos medios de comunicación que construyen enemigos a la medida de la víctima - a quien representan sedienta de venganza-, y contraponen los derechos de las víctimas y los imputados como un juego de todo o nada, generando una imagen de las garantías del procesado como derrotas de las víctimas.

Sin embargo, los derechos de los imputados y de las víctimas no son necesariamente excluyentes, aunque sea ese el modelo que más se difunda y el que más acogida tenga en algunos sectores políticos y judiciales. Por una parte, los derechos de los imputados obran como mecanismo de protección frente al poder de persecución estatal y, por lo tanto, como

28 En la Sentencia C-228 de 2002, M. P. Manuel José Cepeda Espinosa y Eduardo Montealegre Lynett, p. 38, dijo la CC: “Si sus derechos no están limitados a la búsqueda de una reparación económica, la solicitud y presentación de documentos e información relevante también podrá estar orientada a contribuir al esclarecimiento de la verdad y a reducir el riesgo de impunidad y no sólo a demostrar la existencia de un perjuicio ni a cuantificar el daño material. Esta concepción también tiene implicaciones tanto en materia de los recursos que puede interponer contra decisiones que puedan afectar sus derechos a la verdad y a la justicia, como respecto a la necesidad de que las providencias que puedan menoscabar sus derechos sean conocidas oportunamente por la parte civil para que pueda controvertirlas. Por ende, está legitimada, por ejemplo, para impugnar decisiones que conduzcan a la impunidad o no realicen la justicia". 
interdicción de la arbitrariedad pública y privada; y, por otra, los derechos de las víctimas son herramientas de control de la función estatal en general $\mathrm{y}$, en materia penal, mecanismos de control de la forma en que el Estado persigue el delito, lo cual, antes que dotar a la víctima de herramientas para avasallar al procesado, le permite la puesta en marcha del aparato penal y servir de control de la legalidad de las actuaciones de los organismos estatales encargados de la investigación y el juzgamiento, buscando evitar procedimientos ilícitos y las desviaciones de poder (por acción o por omisión).

El anterior no ha sido el camino seguido en Colombia, pues, en nombre de los derechos de las víctimas, tanto la CC como la CSJ han restringido y hasta desconocido claras reglas de garantía existentes en favor del imputado, incluso de rango constitucional. Así ha sucedido, por ejemplo, en el caso de la prohibición constitucional de las penas y medidas de seguridad imprescriptibles (Const. Pol., art. 28), la cual ha sido entendida por la CC como referida solo a la imprescriptibilidad de la sanción, es decir, una vez impuesta en una sentencia debidamente ejecutoriada, y no también al ejercicio de la acción penal. ${ }^{29}$ Tal interpretación obvia el problema consistente en que, una vez admitida la imprescriptibilidad de la acción penal, esta puede conducir a la de la pena, pues posibilitaría una persecución penal infinita, que al fin y al cabo es lo que pretende prohibirse mediante la prohibición constitucional, pues, como explica Pastor (2004), dado el carácter finito de la existencia humana, una pretensión punitiva indefinida es claramente incompatible con el Estado constitucional. Conforme a la interpretación de la CC, por el contrario, mientras la investigación no se dirija en concreto contra sujetos individualizados, el legislador tiene facultad para decidir sobre la imprescriptibilidad o no de la acción penal. ${ }^{30}$

En principio, el argumento de la CC podría entenderse válido, en tanto no existe un derecho humano a la imprescriptibilidad reconocido en los tratados internacionales; antes, por el contrario, estos más bien declaran la imprescriptibilidad de algunos delitos, como sucede, por ejemplo, con aquellos de competencia de la CPI. Ello no significa, sin

29 Ver CC, Sentencia C-620 de 2011, M. P. Juan Carlos Henao Pérez.

30 Ibid. 
embargo, que la Constitución Política no pueda regular la materia de otra manera, toda vez que, como se indicó antes, rige en estos casos la cláusula de interpretación más favorable (Pinto, 1997). Y es que si bien pueden existir razones para considerar la imprescriptibilidad, inindultabilidad o inamnistiabilidad de ciertos delitos, ello también podría ser considerado innecesario desde un punto de vista preventivo o injusto, como sucede cuando ha transcurrido un lapso de tiempo, considerable entre la comisión de la conducta y el juzgamiento, tiempo durante el cual muy seguramente se han presentado cambios importantes tanto en la sociedad como en el sujeto. ${ }^{31} \mathrm{Y}$ dado que el derecho penal protege de manera prioritaria y directa al imputado frente a castigos desproporcionados e injustos, la existencia de límites temporales a la persecución penal encuentra plena justificación; luego, existiendo una prohibición constitucional expresa al respecto, como sucede en Colombia, lo más que podría hacer el legislador sería diferenciar plazos de prescripción en atención a la gravedad de los delitos. ${ }^{32}$

Aún más allá, como ya se explicó, ha ido la CSI, que en el mencionado caso de la 'masacre de Segovia' ${ }^{33}$ aplicó directamente las normas de imprescriptibilidad del Estatuto de Roma a casos de homicidio, ya prescritos, pero que, en opinión de la CSJ, tenían la connotación del genocidio, con el agravante de que se trataba de hechos ocurridos antes de la entrada en vigencia del referido estatuto.

Quizá lo que se pierde de vista es que una declaración de prescripción de la acción no tiene por qué implicar, de forma necesaria, la negación de los derechos de las víctimas, pues el derecho administrativo, por ejemplo, tiene suficientes herramientas para garantizar que en el seno de un proceso por responsabilidad estatal se establezca la verdad y se dispensen los elementos necesarios para la justicia y la reparación. Aún más, la imprescriptibilidad en los delitos de lesa humanidad puede funcionar en determinado momento como un arma de doble filo, que

31 Según explica Silva Sánchez (2008, p. 156), "existe un punto en el que se deja atrás el presente y se entra en la historia, que no debería ser objeto de la intervención penal"; en este mismo sentido se ha pronunciado Pastor (2004).

32 Así lo ha entendido en otros casos la CC, Sentencia C-345 de 1995, M. P. Eduardo Cifuentes Muñoz.

33 Corte Suprema de Justicia, sentencia del 15 de mayo de 2013, Radicado 33118. 
hipotéticamente podría derivar en una prórroga de la impunidad que quiere combatirse, pues posibilitaría al Estado mantener abiertas investigaciones, pero sin interés alguno en concluirlas, con lo que su inoperancia estaría obnubilada por la eventual finalización de una investigación imprescriptible. Por el contrario, la prescripción conforme al derecho interno alertaría a las instituciones penales internacionales sobre la falta de interés del Estado en la investigación y visibilizaría la pasividad o tolerancia del mismo Estado frente a las violaciones de derechos humanos, lo que podría justificar una eventual intervención de la CPI, en virtud del carácter subsidiario de dicha jurisdicción.

\section{A manera de conclusión: el principio de integración penal}

El principio de integración penal consagrado en el artículo $2^{\circ}$ del Código Penal, como ya se indicó, ordena incorporar a este código las normas y postulados sobre derechos humanos consignados en la Constitución Política y en los tratados y convenios internacionales ratificados por Colombia. ${ }^{34}$ En virtud de lo dispuesto en el artículo 13 del Código Penal, estas normas de derechos se incorporan a la legislación penal como normas rectoras, lo cual les otorga una prevalencia sobre las demás normas penales no rectoras, pues tienen un sentido constitucional dada su conexión con el núcleo básico de derechos fundamentales. Ello significa que el carácter rector de estas normas se encuentra fundado no exclusivamente en el artículo 13 del Código Penal, sino sobre todo en la vinculación de su contenido prescriptivo con las normas constitucionales y más concretamente con los derechos humanos y garantías fundamentales (Tamayo Arboleda, 2013); en consecuencia, una vez incorporadas a la legislación penal, estas se dirigen no solo al juez ordinario al momento de interpretar y aplicar la ley penal, sino también al legislador al momento de crearla y al juez constitucional al momento de controlar si el legislador fue respetuoso de los límites constitucionales.

34 Pioneros en este sentido, aún en vigencia de la Constitución de 1886, fueron Fernández Carrasquilla (1988) y Velásquez (1987). 
Dadas las características fundamentales del principio de integración, su relación con el bloque de constitucionalidad (Const. Pol., art. 93) es evidente, aun cuando ello no conduce a una identificación plena. Por una parte, los derechos humanos consagrados en la Constitución y en los tratados internacionales ratificados por Colombia hacen parte del bloque de constitucionalidad, por lo que su prevalencia dentro del orden normativo está dada por la primacía jerárquica de la Constitución sobre la ley. El principio de integración penal, por su parte, cumple la función específica de seleccionar entre tales normas sobre derechos humanos aquellas normas de garantía frente a la actividad punitiva estatal, las cuales por esta vía son incorporadas a la legislación penal colombiana. Luego, en tanto que al derecho constitucional solo le interesa la incorporación de los derechos humanos al orden constitucional (bloque de constitucionalidad), independientemente de si estos son derechos de defensa del ciudadano frente al poder estatal o derechos de prestación del Estado frente al ciudadano, al derecho penal solo le interesa la incorporación de los derechos humanos de defensa frente al poder punitivo del Estado, pues la función de protección de bienes jurídicos se encuentra condicionada por el principio de legalidad y demás principios de garantía, incluso en aquellos casos en los cuales un tratado internacional le impone al Estado, prima facie, el deber de penalizar alguna conducta en particular (como en el caso del genocidio, por ejemplo).

$\mathrm{Al}$ respecto conviene hacer una doble distinción: por una parte, no todas las normas que integran el bloque de constitucionalidad forman parte a su vez del principio de integración penal, pues a este solo pertenecen las normas que restringen el poder penal estatal; en segundo lugar, entre las normas integradas a la legislación penal cabe igualmente distinguir entre aquellas que funcionan como reglas específicas aplicables a problemas concretos y las que tienen un carácter general, pues en un sentido estricto solo estas últimas tienen además el carácter de normas rectoras del derecho penal, en el sentido de condicionar la interpretación de las demás normas penales. Un ejemplo de lo primero sería el caso de la prohibición de la obediencia debida prevista en el artículo $2^{\circ}$ de la Convención contra la Tortura (Ley 70 de 1986), la cual, por vía del bloque de constitucionalidad, se entiende incorporada a la Constitución Política (Bernal Cuéllar, 2003; Uprimny, 2005) y, por vía del principio 
de integración, también a la legislación penal, aun cuando no se trate de una norma rectora; igual podría decirse, en el ámbito de la ejecución de la pena, de las reglas mínimas del tratamiento de las personas privadas de la libertad, aprobadas por el Consejo Económico y Social en sus resoluciones 663C (XXIV) del 31 de julio de 1957 y 2076 (LXII) del 13 de mayo de 1977, las cuales podrían ser entendidas integrantes del bloque de constitucionalidad en sentido amplio, pero no son normas rectoras del derecho penal.

Por el contrario, la norma prevista en el artículo 5.5 de la Convención Americana de Derechos Humanos (y en el artículo 10.3 del Pacto Internacional de Derechos Civiles y Políticos), según la cual "las penas privativas de la libertad tendrán como finalidad esencial la reforma y la readaptación social de los condenados", debe entenderse no solo como un principio constitucional integrado a la legislación vigente, sino también como una norma rectora, toda vez que impone al Estado, con carácter general, limitaciones sobre el contenido de las penas privativas de la libertad, en el sentido de facilitar y en todo caso no obstaculizar la reintegración social del reo, independientemente, en principio, del delito cometido o la personalidad del condenado; vale resaltar que no en vano se trata de una norma recogida en dos de los más importantes documentos jurídicos de derechos humanos, surgidos para la protección de los individuos frente a la actividad estatal; no se trata pues de una finalidad de la pena $\mathrm{y}$, por lo tanto, de un mero principio regulativo dirigido al legislador y demás autoridades públicas para orientar su acción a la consecución de dicho fin; por el contrario, es una de las manifestaciones en el ámbito de la ejecución de la pena del principio de respeto a la dignidad humana, al establecer limitaciones a la pena de prisión, como condiciones de un trato penal mínimamente justo (Cid Moliné, 1998) (o, si se prefiere, menos injusto). De ahí que dicha norma cumpla la función adicional de orientar la interpretación, en el sentido indicado, de las normas penales que regulan la aplicación y ejecución de las penas privativas de la libertad.

La razón por la cual solo las normas limitadoras del poder punitivo estatal se integran a la legislación penal se encuentra en que el derecho penal siempre representa una restricción de derechos fundamentales, primero a través de la coacción de la libertad propia de toda prohibición y luego a través del mecanismo más despiadado del Estado: la pena. 
En consecuencia, el derecho penal es siempre un mal y por ello solo podría justificarse por su necesidad social, y siempre que no resulte una medida desproporcionada e injusta; y es precisamente para evitar una respuesta punitiva de estas características que el derecho penal existe. Luego, así entendidas, las garantías penales son herramientas de protección ciudadana que surgen luego (y no antes) de la ponderación constitucional entre la libertad general de actuar que se reconoce a todo individuo y las necesidades de prevención de los comportamientos que afectan la convivencia social; siendo todo el sistema penal una restricción de derechos fundamentales mediante la utilización del poder violento del Estado, y a la vez una necesidad social, la única forma de predicar legitimidad de dicho poder salvaje es estableciendo contornos limitadores que respeten al ciudadano, intentando mantener el poder del Estado bajo rigurosos controles que le impidan ampliar despóticamente la administración de detenciones, investigaciones y penas, manteniendo al Estado, y su poder penal, como un servicio para el ciudadano en la conformación y mantenimiento de la convivencia pacífica. Esta es la filosofía que informa los tratados y convenios de derechos humanos y ese, por lo tanto, el sentido de su integración al derecho penal.

En esta medida, las normas rectoras son normas jurídicas que en materia penal facilitan la concreción de los límites a la intervención penal estatal y, por lo tanto, como bien explica Fernández Carrasquilla (2011, p. 132), "son verdaderas normas de garantía y por serlo no solo resulta jurídicamente imposible que se utilicen para agravar, desmejorar o desfavorecer los derechos fundamentales del ciudadano, o bien para expandir el sentido de los tipos o el alcance de las penas legales, sino que, además, no garantizarían nada si cualquier otra norma pudiera vulnerar, agraviar o mermar los derechos que ellas amparan, o los marcos hermenéuticos que fijan". Ello significa que dichas normas rectoras deben operar como criterios restrictivos de la incriminación penal, dado que en tal caso el derecho penal se vale de razones para castigar a una persona (es decir, para vulnerar o limitar sus derechos humanos); y por los mismos motivos, deben funcionar como criterios expansivos en el ámbito de la exculpación o la atenuación (Prieto Sanchís, 2011), pues en tales eventos ya no se buscan razones para castigar, sino para no hacerlo o hacerlo en menor grado. 
Conforme a lo anterior, los derechos de las víctimas, si bien pueden entenderse integrados al bloque de constitucionalidad, en estricto sentido no forman parte de la legislación penal sustantiva y mucho menos de sus normas rectoras, pues en realidad el derecho de la víctima a la verdad, justicia y reparación no condiciona en ningún sentido lo que es delito o la pena por imponer. Ello no significa que la víctima carezca de relevancia en el plano del derecho penal material, pues la puede tener en la determinación de lo penalmente ilícito (a partir de la denominada victimodogmática), como en su contribución a la posible recanalización del conflicto por una vía diferente a la penal o por las vías alternativas definidas por el mismo derecho penal. Solo que en estos casos el rol de la víctima no viene impuesto por normas internacionales de derechos humanos, sino por otros principios penales limitadores, tales como el de protección de bienes jurídicos y de intervención mínima (Schünemann, 2012). Distinto es cuando los derechos de las víctimas se miran desde el punto de vista del derecho procesal penal, pues tanto el imputado como la víctima tienen derecho al proceso y en esa medida el procedimiento debe garantizar su reconocimiento y posibilidades de actuación, tal como lo dispone el artículo 11 del Código de Procedimiento Penal. Así entendidos, como ya se indicó, los derechos de las víctimas en materia penal tienen por objetivo, más que sumar una parte agregada a la fiscalía en la persecución penal, dotar a la víctima de posibilidades para buscar salidas al conflicto diferentes a la penal o bien para ejercer un control de las actuaciones de la justicia penal, a fin de evitar no la absolución del procesado, sino la ilegalidad de los procedimientos. De esta manera, los derechos de las víctimas en materia penal adquieren un espacio propio que no se superpone al de los fines de protección del procesado, por cuanto más bien operan como mecanismos independientes de garantía frente a las autoridades implicadas y no frente al procesado.

Debe reconocerse que, conforme a este fundamento, la determinación concreta de las normas que se integran a la legislación penal -y aún más si se trata de dilucidar su carácter rector- es una tarea compleja, que requiere el análisis específico de cada uno de los derechos humanos incorporados, a fin de determinar su impacto en materia de control del poder punitivo estatal; y solo en la medida en que pueda erigirse en mecanismo de garantía frente a dicho poder debe entenderse integrado 
y prevalecer en el ordenamiento jurídico penal. Ello, por supuesto, implica la exclusión del discurso punitivo de los derechos humanos, más interesado en la flexibilización, reformulación y hasta exclusión de las garantías penales que en la protección efectiva de los derechos.

\section{Referencias}

Álvarez, J. C. (2012). Las vicisitudes del principio de legalidad a propósito de la persecución penal de crímenes contra la humanidad. En D. Araque (Ed.), Estudios de derecho penal. Libro homenaje a Juan Fernández Carrasquilla (pp. 59-81). Medellín: Universidad de Medellín.

Ambos, K. (2000). Sobre el fundamento jurídico de la Corte Penal Internacional. Un análisis del Estatuto de Roma. Revista de Derecho Penal y Criminología, (5), 127-169.

Aponte, A. (2006). Guerra y derecho penal de enemigo. Reflexión crítica sobre el eficientismo penal de enemigo. Bogotá: Ibáñez.

Arango Olaya, M. (2004). El bloque de constitucionalidad en la jurisprudencia de la Corte Constitucional colombiana. Precedente. Anuario Jurídico, 79-102. Recuperado de https://www.icesi.edu.co/revistas/index.php/precedente/ article/view/1406/1805

Beltrán, E. (1998). Crimen sin castigo. Impunidad en América Latina. América Latina Hoy, (20), 5-8.

Bernal Cuéllar, J. (2003). Bloque de constitucionalidad y derecho penal. En E. Montealegre Lynett (Ed.), El funcionalismo en derecho penal. Libro homenaje al profesor Günther Jakobs (pp. 187-207). Bogotá: Universidad Externado de Colombia.

Castex, F. (2008). Arancibia Clavel, una elocuente muestra del neopunitivismo local. En D. R. Pastor (Dir.) \& N. Guzmán (Coord.), Neopunitivismo y neoinquisición:un análisis de las políticas y prácticas penales violatorias de los derechos fundamentales del imputado, (pp. 91-135). Buenos Aires: Ad-Hoc.

Cid Moliné, J. (1998). Derecho a la reinserción social. Consideraciones a propósito de la reciente jurisprudencia constitucional en materia de permisos. Jueces para la Democracia, (32), 36-48.

Doménech Pascual, G. (2007). Los derechos fundamentales a la protección penal. Revista Española de Derecho Constitucional, (78), 333-372. 
Fajardo Arturo, L. A. (2009). Efectos del bloque de constitucionalidad de prescripción de la acción penal en Colombia. Civilizar, 9(17), 65-77.

Fernández Carrasquilla, J. (1988). Los derechos humanos como barrera de contención y criterio autorregulador del poder punitivo. Nuevo Foro Penal, (39), 58-88.

Fernández Carrasquilla, J. (2011). Derecho penal, parte general. Principios y categorías dogmáticas. Bogotá: Ibáñez.

Ferrajoli, L. (1995). Derecho y razón. Teoría del garantismo penal.. Madrid: Trotta.

Garland, D. (2005). La cultura del control. Crimen y orden social en la sociedad contemporánea. Barcelona: Gedisa.

Hulsman, L., E Bernat de Celis, J. (1984). Sistema penal y seguridad ciudadana. Barcelona: Ariel.

Lopera Mesa, G. P. (2006). Principio de proporcionalidad y ley penal. Madrid: Centro de Estudios Constitucionales.

Méndez, J. E. (1997). Derecho a la verdad frente a las graves violaciones a los derechos humanos. En La aplicación de los tratados sobre derechos humanos por los tribunales locales (pp. 517-540). Buenos Aires: CELS.

Nanzer, A. (2009). La satisfacción de la víctima y el derecho al castigo. En D. R. Pastor (Dir.) \& N. Guzmán (Coord.), El sistema penal en las sentencias recientes de los órganos interamericanos de protección de los derechos humanos (pp. 353376). Buenos Aires: Ad-Hoc.

Pastor, D. (2004). Tensiones: ¿derechos fundamentales o persecución penal sin límites? Buenos Aires: Del Puerto.

Pastor, D. (2006). El poder penal internacional: una aproximación crítica a los fundamentos del Estatuto de Roma. Barcelona: Atelier.

Pastor, D. (2009). Encrucijadas del derecho penal internacional y del derecho internacional de los derechos humanos. Bogotá: Pontificia Universidad Javeriana.

Pérez Toro, W. F. (2000). Guerra y delito en Colombia. Estudios Políticos, (16), 11-41.

Pinto, M. (1997). El principio pro homine. Criterios de hermenéutica y pautas para la regulación de los derechos humanos. En M. Abregu \& C. Courtis (Eds.), Aplicación de los tratados sobre derechos humanos por los tribunales locales (pp. 163-171). Buenos Aires: Del Puerto.

Pinzón Muñoz, C. E. (2012). El principio de integración (artículo $2^{\circ}$ del Código Penal) en Colombia: ¿garantía del imputado o herramienta de punición? Nuevo Foro Penal, (79), 71-99.

Pratt, J. (2007). Penal populism. London: Routledge, Taylor E Francis Group.

Prieto Sanchís, L. (2011). Garantismo y derecho penal. Madrid: Iustel. 
Roht-Arriaza, N. (1990). State responsability to investigate and prosecute grave human rights violations in international law. California Law Reviez, 78(2), 449-513.

Schünemann, B. (2012). Protección de bienes jurídicos, ultima ratio y victimodogmática. Sobre los límites inviolables del derecho penal en un Estado de derecho liberal. En A. von Hirsch, K. Seelmann \& W. Wohlers (Eds.), Límites al derecho penal. Principios operativos en la fundamentación del castigo (pp. 6385). Barcelona: Atelier.

Silva Sánchez, J. M. (2001). La expansión del derecho penal. Aspectos de la política criminal en las sociedades posindustriales ( $2^{\mathrm{a}}$ ed.). Madrid: Civitas.

Silva Sánchez, J. M. (2008). ¿Nullum crimen sine poena? Sobre las doctrinas penales de la 'lucha contra la impunidad' y del 'derecho de la víctima al castigo'. Derecho Penal y Criminología, (86-87), 149-171.

Sotomayor, J. O. (2007). Las recientes reformas penales en Colombia: un ejemplo de irracionalidad legislativa. Nuevo Foro Penal, (71), 13-66.

Sotomayor, J. O. (2013). El deterioro de la función de garantía del derecho penal actual. En F. Velásquez et al. (Eds.), Derecho penal y crítica al poder punitivo del Estado. Libro homenaje a Nódier Agudelo Betancur (pp. 330-360). Bogotá: Ibáñez-U. Eafit-U. Pontificia Bolivariana-U. Sergio Arboleda-U. de los Andes. Tamayo Arboleda, F. L. (2013). El principio de tipicidad como límite al poder punitivo del Estado (comentarios al artículo 10 del Código Penal colombiano). Nuevo Foro Penal, (80), 34-81.

Uprimny, R., E Saffon Sanín, M. P. (2006a). Derecho a la verdad: alcances y límites de la verdad judicial. En R. Uprimny et al. (Eds.), ¿Justicia transicional sin transición? Verdad, justicia y reparación para Colombia (pp. 139-171). Bogotá: Dejusticia.

Uprimny, R., E Saffon Sanín, M. P. (2006b). Justicia transicional y justicia restaurativa: tensiones y complementariedades. En R. Uprimny et al. (Eds.), ¿Justicia transicional sin transición? Verdad, justicia y reparación para Colombia (pp. 109-138). Bogotá: Dejusticia.

Uprimny, R. (2005). El bloque de constitucionalidad en Colombia. Recuperado de http:// redescuelascsa.com/sitio/repo/DJS-Bloque_Constitucionalidad(Uprimny).pdf Uprimny, R. (2008). Bloque de constitucionalidad, derechos humanos y proceso penal. Bogotá: Consejo Superior de la Judicatura.

Velásquez, F. (1987). Principios rectores de la nueva ley procesal penal. Bogotá: Temis. 